\title{
To What Extent Does Punishment Insensitivity Explain the Relationship Between Callous-unemotional Traits and Academic Performance in Secondary School Students?
}

Antisocial behaviour is a challenge in schools, predicting poor student academic engagement and performance, truancy, school exclusion, and teacher-student conflict (Carroll, Houghton, Durkin, \& Hattie, 2009; Doumen et al., 2008), and is a major contributor to teacher stress, burnout and decision to leave the profession (Spilt, Koomen, \& Thijs, 2011). The time teachers spend managing disruptive behaviour in the classroom not only negatively impacts the learning of individual students who misbehave, but also that of their classmates (Westling, 2010). The effective use of teacher discipline is known to promote children's academic achievement (Pasternak, 2013), while the absence of discipline or harsh, inconsistent discipline predict poor achievement (Carrell \& Hoekstra, 2009; Yang, 2009). The negative effects of academic underachievement are wide-ranging, including disengagement from school and early drop-out, increased risk for criminal offending, unemployment and lower incomes, health problems, early mortality and public service usage (Moretti, 2005; Doll, Spies, \& Champion, 2012). As such, academic underachievement has been a prominent issue for antisocial children for a long time.

There is increasing evidence for callous-unemotional (CU) traits as a temperamental risk factor for poor school outcomes for antisocial children. CU traits comprise low empathy, lack of guilt, shallow emotions and a lack of concern about performance (Frick et al., 2014). Antisocial children with elevated CU traits show a more severe, aggressive and chronic pattern of antisocial behaviour, unique biological, emotional, social-motivational and cognitive correlates, and reduced responsiveness to intervention compared to antisocial children with low levels of these traits (Allen, Hwang, \& Huijding, 2020). The most recent edition of the Diagnostic and Statistical Manual of Mental Disorders (DSM-5; American Psychiatric Association, 2013) therefore introduced CU traits as a specifier for conduct 
disorder under the label of 'limited prosocial emotions'. Educational classification systems, however, have yet to acknowledge the role of CU traits in relation to students' poor behavioural and academic adjustment, despite its clear potential to inform education policy and practice (Warren, Jones, \& Frederickson, 2015).

One of the most robust findings in relation to factors underlying the association between antisocial behaviour and poor academic achievement is the presence of verbal ability deficits in antisocial youth (Allen, 2017). This relationship remains significant even after controlling for socioeconomic status, ethnicity, and test-taking motivation (Moffitt, 1993). However, there is consistent evidence that $\mathrm{CU}$ traits are related to poor academic achievement even when accounting for the influence of externalizing problems (\#\#\#\# blinded for peer review; Horan, Brown, Jones, \& Aber, 2016; Vaughn et al., 2011), despite the fact that $\mathrm{CU}$ traits are not associated with deficits in verbal intelligence (Allen, Briskman, Humayun, Dadds, \& Scott, 2013; DeLisi et al., 2011), This link between CU traits and poor achievement has been established in studies employing person-centred and variable-centred approaches to analysis, across different subjects (e.g., English/Reading Achievement, Maths, Science), forms of assessment (e.g., teacher questionnaire ratings, standardized test scores) and during both the primary and secondary school periods (\#\#\#, blinded for peer review; Ciucci, Baroncelli, Franchi, Golmaryami, \& Frick, 2014; DeLisi et al., 2011; Horan et al., 2016; Vaughn et al., 2011). This has led to the suggestion that there may be heterogeneous risk pathways for poor academic outcomes for antisocial children with high versus low levels of CU traits (\#\#\#, blinded for review, DeLisi et al., 2011; Horan et al., 2016).

One critical way in which antisocial children with CU traits differ from antisocial children without these traits is decreased sensitivity to punishment cues, including reduced recognition and responses to others' expressions of fear, pain or sadness (Dawel, O'Kearney, McKone, \& Palermo, 2012; Jones, Laurens, Herba, Viding, \& Barker, 2009; Lockwood et al., 
2013). Children with CU traits tend to pursue desired goals using aggressive or antisocial means, showing little concern for the potential consequences of their behaviour, including anticipated feelings of guilt, others' distress or disciplinary action (Pardini \& Byrd, 2012). Theory has identified a lack of affective discomfort in response to discipline as one mechanism explaining poor conscience development and reduced responsiveness to discipline-based parenting strategies for children with CU traits (Blair, 2017; Hawes, Price, \& Dadds, 2014; Kochanska, 1993). This lack of arousal in response to discipline prevents avoidance learning from taking place, and the child fails to internalise the moral or social norm that his or her parent (or teacher) wishes to convey (Pardini \& Frick, 2013). Consistent with this view, antisocial children high in CU traits show less distress when placed in time out than children low in CU traits (Bansal et al., 2019; Hawes \& Dadds, 2005). Uncaring or insensitive responses to punishment have also been proposed as a mechanism explaining the link between CU traits and poor achievement (DeLisi et al., 2011; Horan et al., 2016). DeLisi et al. (2011) argued that children with CU traits are not distressed by the consequences of academic failure and subsequently lack the motivation to perform to the expectations of teachers or parents. The decreased sensitivity of children with CU traits to teacher discipline therefore leads to reduced school engagement and increased disruptive behaviour. Furthermore, Horan et al. (2016) suggested that CU traits may elicit harsher responses from their teachers due to this punishment insensitivity, with these negative teacher-student interactions exacerbating poor academic adjustment in these at-risk children.

Few studies have investigated links between CU traits and teacher discipline, but the existing evidence suggests that findings for reduced sensitivity to parental discipline may also apply to teacher-child interaction (Allen, Morris, \& Chhoa, 2016; \#\#\#\#, blinded for peer review). For example, in qualitative interviews, secondary school teachers reported that discipline strategies were less effective for boys with elevated CU traits than their typically 
developing peers (Allen et al., 2016). Qualitative analysis of teacher interviews of a subset of students in the current sample who self-reported as high $(n=24)$ and low in CU traits $(n=$ 23) indicated that teachers perceived students high in CU traits as more resistant to discipline, and in greater need of monitoring and feedback to engage them in schoolwork (\#\#\#, blinded for peer review). In the preschool context, time-out implemented by teachers was less effective for children high in CU traits compared to those low in CU traits (Garcia, Graziano, \& Hart, 2018). Finally, a recent study found a moderating effect of CU traits on teacher harsh discipline and school engagement in South Korean primary school students, where teacher's harsh discipline at the start of the school year predicted less engagement in children with high, but not low levels of CU traits across the school year (Hwang, Waller, Hawes, \& Allen, 2020). There were no reciprocal effects between CU traits and teacher harsh discipline; harsh teacher discipline predicted later antisocial behaviour, but not CU traits. These findings are consistent with theory highlighting the role of punishment insensitivity in CU traits (Blair 2017; Pardini \& Frick, 2013), and suggest that these traits may even act as a protective factor against harsh teacher discipline.

Punishment insensitivity has yet to be formally tested as a mechanism explaining the link between CU traits and poor academic performance (\#\#\#, blinded for peer review; DeLisi et al., 2011). This is surprising given that a better understanding of mechanisms explaining how CU traits affect school success may help to identify students at risk for low grades. We examine this possibility in students in years 7 to 9 of secondary school, a period when students simultaneously encounter more varied, challenging school work and higher expectations from teacher to show independence in their learning compared to the primary school period. This stage of schooling also features a shift from primarily receiving instruction from one classroom teacher, to having different teachers for different subjects. This means that there is less opportunity for secondary school teachers to develop a better 
understanding of their student's needs and to form a close relationship than in earlier periods of schooling. For these reasons, managing academic pressure may be heightened during this period and students are more likely to 'burn out' or disengage from schoolwork (Midgley \& Urdan, 1992; Salmela-Aro \& Upadyaya, 2014).

In this study, we sought to explore punishment insensitivity as a mechanism explaining the association between CU traits and poor academic outcomes, controlling for sociodemographic disadvantage and externalizing problems. Student grades in the three core subjects of the National Curriculum for England: English, Maths and Science were assessed using curriculum set assessments. Student grades in all three subjects were examined as separate outcomes which were allowed to covary in one model while controlling for teacher effects. This allowed us to examine potential differences in pathways for each subject grade in relation to different classroom characteristics or teaching methods across subjects, while simultaneously accounting for relationships between subject grades. We predicted that $\mathrm{CU}$ traits would be significantly related to English, Maths and Science grades, and that these associations would work indirectly through punishment insensitivity.

\section{Method}

\section{Participants}

Participants were students aged 11 to 14 years $(M=12.50, S D=0.96)$ in Years 7 to 9 of a state secondary school in England. Of the 503 students that were approached, 437 (87\%) agreed to participate in the present study. Students comprised 216 girls and 221 boys. Most children were White $(95 \%, n=420)$ and had English as their first language $(77 \%)$. The remainder of the sample $(4 \%, n=17)$ identified their ethnicity as follows: Black, Mixed Black and White, Asian, or Mixed White and Asian. Only a minority of children belonged to a single-parent family (16\%) and 46 students (11\%) were eligible for free school meals. 
These are largely consistent with the UK's average rate of single-parent families and eligible students for free school meals (22\% and 13\%, respectively) (Department for Education, 2017; Office for National Statistics, 2017). Children attended different classes for English ( $n$ $=8)$, Science $(n=9)$, and Maths $(n=9)$ based on ability level. The number of children per classroom ranged between 15 and 31 children $(M=21.38, S D=4.07)$, while the number of participating students ranged between 12 and 30, with a median of 21 students.

\section{Procedure}

Prior to data collection, study procedures were approved by the university ethics review board. An invitation letter was sent to the school containing information about the research and seeking permission to approach students to participate. The school sent parents an optout parental consent form; parents were given a week to return the form if they did not want their child to participate. No reply slips were returned. On the day of the assessment the investigator informed students of the study aims and gave students the option of omitting certain items or returning the questionnaire uncompleted without giving a reason. Students completed the questionnaires in their regular lesson time in class groups under exam conditions. All data collection was conducted on the same day.

\section{Measures}

Academic Performance. Child grades for English, Maths, and Science were collected from school records. These are core, compulsory subjects in state secondary schools in England during Years 7 to 9 (Key Stage 3). Teachers assess child achievement using compulsory set assessments corresponding to the National Curriculum programmes of study in England (see www.gov.uk/nationalcurriculum/overview), with aggregated scores 
converted to final grades using a 9-point scale. Higher scores indicate a higher level of student achievement.

Callous-Unemotional Traits. Child report of CU traits was assessed using the Inventory of Callous Unemotional Traits (ICU; Frick, 2004). The revised scale excludes two items from the original 24-item ICU (i.e., item 2 and item 10) due to poor item-total correlations of less than 0.10 (Ray, Frick, Thornton, Steinberg, \& Cauffman, 2016). Children rate each item on a 4-point Likert scale from 0 (not true at all) to 3 (definitely true) (e.g., 'I care about how well I do at school', 'I'm concerned about the feelings of others'). The revised 22-item ICU scale has shown good reliability and construct validity in previous studies with alphas ranging from .78 to .81 and showing significant associations between higher total ICU scores, low empathy and more severe aggression (Kimonis et al., 2008; Ray et al., 2016). Cronbach's alpha was .79 for the 22-item ICU in the current sample.

Punishment insensitivity. The punishment insensitivity scale of the Multidimensional Assessment of Preschool Disruptive Behavior (MAP-DB; Wakschlag et al., 2012) was used to assess response to discipline. The punishment dimension consists of 7 items rated on a 6 point-Likert scale from 0 (never) to 5 (always). The MAP-DB is a parent report measure that shows good reliability and validity (Nichols et al., 2015; Wakschlag et al., 2012). We used a modified version of the punishment insensitivity scale that adapted the wording for child self-report (e.g., 'You do not care when you are punished', 'You continue to misbehave no matter what your teacher does'). The child-report version has shown good internal consistency $($ alpha $=.82)$ and significant associations with teacher and child report of CU traits and antisocial behaviour in a previous study of English secondary school students (Allen et al., 2016). Cronbach's alpha in the current sample was .88.

Externalizing problems. To assess children's externalizing problems, we selected 9 items from the Reward Sensitivity scale of the revised Sensitivity to Punishment and 
Sensitivity to Reward Questionnaire (SPSRQ-C; Colder et al., 2011) that tap into hyperactivity and deficits in response inhibition. As the self-report SPSRQ is designed for adults (Torrubia et al., 2001), several items are not suitable for children (e.g., 'When you start to play a slot machine, is it difficult for you to stop?', 'Do you often take the opportunity to pick up people you find attractive?'). We therefore modified the wording of items from the parent-report SPSRQ-C to be suitable for child report. For example, 'Your child often has trouble resisting the temptation of doing forbidden things' was changed to 'You often have trouble resisting the temptation to do forbidden things'. Children rated the 9 items on a 5point-Likert scale from 1 (strongly disagree) to 5 (strongly agree). Youth report on a modified version of standard SPSRQ (Torrubia et al., 2001) that covers similar items and changes to item wording to the child-report SPSRQ-C has shown good reliability and validity (Vandeweghe et al., 2016). Confirmatory factor analysis in a previous study featuring the current sample (\#\#\#\#, blinded for review) found that the externalizing problems scale had good construct validity, with this model showing an excellent fit to the data (CFI=1.00 SRMR=.01, RMSEA=.00). Alpha for the externalizing problems scale was .75 in the current sample. Teacher report of externalizing problems on the Strengths and Difficulties Questionnaire (SDQ; Goodman, 1997) was also significantly related to child-report on this externalizing problems scale $(r=.32, p=.05)$ in a subset of this sample $(n=38)$.

Sociodemographic Characteristics. A child report questionnaire assessed their age in years, self-reported gender $(1=$ male, $0=$ female $)$, English as a second language $(1=$ yes, $0=$ no). As an indication of socio-economic status, we used family composition $(1=$ singleparent, $0=$ two parent) and eligibility for free school meals $(1=\mathrm{yes}, 0=\mathrm{no})$.

\section{Data Analysis}


Analyses were performed in SPSS statistical software (version 25) (IBM Corporation, 2017) and the Mplus statistical package (version 8) (Muthén and Muthén, 2017). We first explored the descriptive statistics and bivariate correlations among the study variables. Then we fitted a Structural Equation Model (SEM) to test if the association between CU traits and academic outcomes could be explained by punishment insensitivity. In order to take missing data into account ( $\%$ of missingness in each variable ranged from 0 to 5.26, see Table 1 ), full information maximum likelihood estimation (FIML) was used. The following indices were used to check model fit: Chi-Square Test of Model Fit, Comparative Fit Index (CFI), TuckerLewis Index (TLI), Standardized Root Mean squared Residual (SRMR), and Root Mean Square Error of Approximation (RMSEA). CFI and TLI values higher than .95 are generally considered to indicate good fit, with values between .90 and .95 indicating acceptable fit (Hox \& Bechger, 1998). Likewise, SRMR values lower than .05 indicate good model fit and values between .05 and .10 indicate acceptable fit. RMSEA is considered to indicate good fit if the value is lower than .05 and an acceptable fit if the value is between .05 and .08 (Hu \& Bentler, 1999). According to the above recommendations, the model showed a good fit in the current sample $\left[\chi^{2}(d f=71)=129.22, p<.001 ; \mathrm{CFI}=.94 ; \mathrm{TLI}=.90, \mathrm{SRMR}=.02 ; \mathrm{RMSEA}=.04\right]$. All academic outcomes were examined in the same model and were allowed to covary. The sample was nested within the classroom for each subject (English, $n=8$; Maths, $n=9$, Science, $n=9$ ), and therefore multilevel modelling was conducted in a previous study (\#\#\#, blinded for peer review) that featured the same sample. However, the current SEM model featured a large number of parameters $(n=558)$ and a small number of clusters (range, $n=$ 8-9), which can lead to poor estimation accuracy in a multilevel model (Meuleman \& Billiet, 2009; Schunck, 2016). Hence, we did not proceed with this approach. The intra-class correlations (ICCs) of each subject ranged from .00 to .12, therefore we created dummy variables for each classroom and used them as covariates to control for potential clustering 
effects. We also included the following covariates in the model: child age, self-reported gender, single parent household, free school meals, English as a second language, and externalizing problems.

\section{Results}

\section{Descriptive Analyses}

Table 1 shows the descriptive statistics and bivariate correlations among the study variables. The mean score of CU traits was similar to those in previous studies of community samples with a similar age range (Essau, Sasagawa, \& Frick, 2006; Roose, Bijttebier, Decoene, Claes, \& Frick, 2010). Grades from all three subjects were significantly negatively related to child externalizing problems, $\mathrm{CU}$ traits, and punishment insensitivity. CU traits were positively related to externalizing problems and punishment insensitivity. Externalizing problems also were significantly positively related to punishment insensitivity. Age was negatively related to English and Maths grades, but not Science grades. English, but not Maths and Science grades were higher for girls than boys. Science grades, but not English and Maths grades, were lower for students who receive free school meals. Both Maths and Science grades were lower for students from a single parent family or for whom English is a second language. Punishment insensitivity was higher for for boys than girls, and higher for students from a single parent family or who receive free school meals.

\section{Structural Equation Modelling and Mediation Analysis}

Results from the SEM investigating potential pathways from CU traits to school grades are presented in Figure 1. We examined all academic domains in one model and Table 2 presents all paths from CU traits to punishment insensitivity and each academic grade. 
Child's age, gender, and English as a first language were significant predictors of English grade, independently of other covariates. Similarly, child's age, family status, and first language were significant predictors of Maths grade, while a family status, free school meals, and first language predicted lower Science grades. However, the effects of CU traits on academic grades were not explained after we controlled for all the covariates and the mediator.

Regarding the path between CU traits and punishment insensitivity, we found that CU traits was a significant predictor of punishment insensitivity even after controlling for externalizing problems, gender, and socio-economic status indexed by membership of a single-parent household and eligibility for free school meals. However, this association did not, in turn, predict English grades. In contrast, CU traits were significantly related to higher punishment insensitivity, which in turn predicted poorer Maths grades. Although CU traits were not directly associated with Maths grades after controlling for confounders, the indirect effect of punishment insensitivity on the link between CU traits and Maths grade was significant (Table 3). Likewise, CU traits were indirectly associated with Science grades via punishment insensitivity (Table 3).

\section{Discussion}

This study is the first to formally test a potential mechanism explaining the relationship between CU traits and poor academic achievement in English, Maths and Science. The findings partly supported our hypothesis, with punishment insensitivity explaining the association between CU traits and low grades in Maths and Science. Importantly, indirect associations were present between CU traits and Maths and Science grades via punishment insensitivity when accounting for teacher effects as well as student age, gender, sociodemographic disadvantage, and externalizing problems. Specifically, CU traits were 
positively associated with punishment insensitivity, which in turn were negatively associated with academic performance in Maths and Science. Punishment insensitivity is a wellestablished correlate of CU traits (Frick et al., 2014), and past research has shown that CU traits are related to impairment in academic performance in a range of disciplines (Ciucci et al., 2014; Horan et al., 2016). Consistent with theory (DeLisi et al., 2011; Horan et al., 2016), our study extends this work and makes a meaningful contribution to the current theory by identifying punishment insensitivity as a mechanism explaining the association between $\mathrm{CU}$ traits and poor academic outcomes. Furthermore, results revealed complete mediation for both Maths and Science grades, suggesting that punishment insensitivity plays a significant role in explaining the link between CU traits and poor achievement in these two subjects. Findings suggest that teachers are likely to need more intensive support and training to implement discipline strategies effectively with students high in CU traits, and that if successful, this additional support may have flow-on benefits for students' performance in Maths and Science. Although there is one teacher-child interaction-based intervention approach to enhancing academic achievement, the My Teaching Partner-Secondary programme (Allen, Pianta, Gregory, Mikami, \& Lun, 2011), existing interventions aiming to improve academic performance in the secondary school period have largely focused on literacy development (Ofsted, 2013). Our findings suggest that interventions aiming to promote academic performance in antisocial children should include greater support for teachers in the implementation of calm, consistent non-physical discipline for children with elevated CU traits.

CU traits were significantly related to lower English grades, consistent with past research showing a relationship between CU traits and poor reading ability (DeLisi et al., 2011; Horan et al., 2016; Vaughn et al., 2011). However, contrary to our hypothesis, findings indicate that factors other than punishment insensitivity influence the link between CU traits 
and low English grades. One explanation for this finding relates to the different structure and format of these subjects. Maths and Science lessons follow a more structured, sequential pathway than English, with student completion of academic work dependent on their understanding of earlier content and their ability to apply previously learnt skills (Johnson, 2000; Stodolsky \& Grossman, 1995). Qualitative findings suggest that students with elevated CU traits are more likely to be sent out of class (\#\#\#, blinded for peer review), and may therefore miss out on teaching that is essential for the completion of tasks in Maths and Science. Another explanation is that verbal skills are easier to 'pick up' outside of the classroom (Berninger, Abbott, Vermeuleu, \& Fulton, 2006). As such, English performance may not be as dependent on sensitivity to discipline as Maths or Science (Slater, Davies, \& Burgess, 2012). Finally, deficits in processing emotional language may reduce the ability of children with CU traits to comprehend the more subtle or contextual aspects of language (Hiatt \& Newman, 2006). Therefore, emotion processing deficits may be an alternative mechanism explaining the link between CU traits and English performance. Indeed, theory has identified a number of mechanisms that may explain the association between CU traits and low grades, including low intrinsic motivation and problematic peer interactions (\#\#\# blinded for review; DeLisi et al., 2011), as well as additional dimensions of teacher-child interaction including teacher reward-based strategies, instructional methods, and teacherstudent relationship quality (DeLisi et al., 2011; Horan et al., 2016; Hwang et al., 2020). Future studies should include a broad range of child dispositional and contextual risk factors to examine their relative contributions to the link between $\mathrm{CU}$ traits and poor academic achievement in different disciplines.

The present study findings should be interpreted in light of several limitations. We tested the associations between CU traits, punishment insensitivity and academic performance cross-sectionally which does not allow us to determine the direction of 
relationships between these constructs over time. However, we estimated all paths among the main study variables simultaneously through the SEM analysis. Therefore, more appropriate inferences regarding the nature of the dual roles of the mediator as both a cause and an effect can be made compared to the use of separate regression analyses. Given the absence of prior research on potential mechanisms explaining the link between $\mathrm{CU}$ traits and poor academic performance, initial investigation within a cross-sectional design provides useful information to inform longitudinal research that is by nature more time and resource-intensive. Our sample was recruited through one state secondary school in England. However, we had a high participation rate and the sociodemographic characteristics of our sample were largely similar to those of the English population when compared to national statistics (see \#\#\#\#\# blinded for review).

Another limitation is that $\mathrm{CU}$ traits and punishment insensitivity were assessed solely on the basis of child report, therefore significant relationships between these variables may reflect shared method variance. Future research should include teacher, parent and child perspectives to gain a more comprehensive view of child characteristics and behaviour. Child self-report may also be prone to bias due to the presence of CU traits, externalizing problems and/or poor quality relationships with teachers. Classroom observation methods would enable a more objective assessment of children's responsiveness to discipline, as well as determining whether teachers are implementing discipline strategies in an effective manner. Current findings need to be replicated in the primary school setting, given that the secondary school period features increased academic demands and higher expectations for student behaviour and independence in combination with less intensive support from teachers-potentially altering the nature and strength of relationships between $\mathrm{CU}$ traits, punishment insensitivity and academic performance. Finally, given evidence for differences in the presentation and correlates of CU traits in East Asian and Western nations (Allen, Shou, Wang \& Bird, 2020; 
Sng, Hawes, Hwang, Allen, \& Fung, 2020), and differences in teacher classroom management practices and means of assessing student academic achievement (Lewis, Romi, Qui, \& Katz, 2005; Romi, Lewis, \& Roache, 2013), there may be cultural variation in the relationships between CU traits, punishment insensitivity and school grades. Future research should strive to investigate cultural differences in the interplay between CU traits and teacher-child interaction.

School success is vital in establishing healthy emotional and behavioural development (Henry, Knight, \& Thornberry, 2012). The current study findings are the first to show that insensitivity to discipline appears to be an important mechanism through which CU traits is related to poor academic performance in Maths and Science, but not English. However, replication is needed given the novelty of our findings, preferably in a multi-informant, multimethod longitudinal design. Our findings support current theories highlighting the importance of inter-relationships between child temperament and sensitivity to discipline for the academic performance (DeLisi et al., 2011; Horan et al., 2016). Future research should formally test whether components of school-based interventions promoting the effective use of teacher discipline represent a mechanism of change for academic outcomes of students with elevated CU traits. $\mathrm{CU}$ traits has shown great utility in explaining differential response to treatment (Frick et al., 2014). Therefore, identifying the mechanisms linking CU traits and poor school outcomes informs our understanding of potential targets for school-based intervention personalized on the basis of temperamental risk. Our understanding of how best to support children with elevated CU traits in Maths and Science may also benefit from investigating alternative means of promoting student achievement to discipline, such as teachers' use of rewards and strategies aimed at promoting teacher-student relationship quality. 


\section{$\underline{\text { References }}$}

Allen, J.L. (2017). Intelligence. In C. J. Schreck, M.J. Leiber, \& H. Ventura Miller (Eds), The encyclopedia of juvenile delinquency and justice. Wiley

Blackwell. https://doi.org/10.1002/9781118524275

Allen, J. L., Briskman, J., Humayun, S., Dadds, M. R., \& Scott, S. (2013). Heartless and cunning? Intelligence in adolescents with antisocial behavior and psychopathic traits. Psychiatry Research, 210(3), 1147-1153. https://doi.org/10.1016/j.psychres.2013.08.033

Allen, J. L., Hwang, S., \& Huijding, J. (2020). Disruptive behavior disorders. In P. Leman, A. James (Eds.), The Encyclopaedia of Child and Adolescent Development Part II:

Adolescent Development, Volume IX - Social Development in Adolescence. Wiley Blackwell. https://doi.org/10.1002/9781119171492.wecad448

Allen, J. L., Morris, A., \& Chhoa, C. Y. (2016). Callous-unemotional (CU) traits in adolescent boys and response to teacher reward and discipline strategies. Emotional and Behavioural Difficulties, 21(3), 329-342. https://doi.org/10.1080/13632752.2016.1165968

Allen, J. L., Shou, Y., Wang, M. C., \& Bird, E. (2020). Assessing the measurement invariance of the Inventory of Callous-Unemotional traits in school students in China and the United Kingdom. Child Psychiatry and Human Development, 1-12. https://doi.org/10.1007/s10578-020-01018-0

Allen, J. P., Pianta, R. C., Gregory, A., Mikami, A. Y., \& Lun, J. (2011). An interactionbased approach to enhancing secondary school instruction and student achievement. Science, 333(6045), 1034-1037. doi: 10.1126/science.1207998 
American Psychiatric Association. (2013). Diagnostic and statistical manual of mental disorders (DSM-5®). American Psychiatric Publications. Washington, DC: Author.

Bansal, P. S., Haas, S. M., Willoughby, M. T., Coles, E. K., Pelham Jr, W. E., \& Waschbusch, D. A. (2019). A pilot study of emotional response to time-out in children with conduct problems and callous-unemotional traits. Psychological Reports, 123(5), 2017-2037. https://doi.org/10.1177/0033294119884014

Berninger, V. W., Abbott, R. D., Vermeulen, K., \& Fulton, C. M. (2006). Paths to reading comprehension in at-risk second-grade readers. Journal of Learning Disabilities, 39(4), 334-351. https://doi.org/10.1177/00222194060390040701

Blair, R. J. R. (2017). Emotion-based learning systems and the development of morality. Cognition, 167, 38-45. https://doi.org/10.1016/j.cognition.2017.03.013

Carrell, S. E., \& Hoekstra, M. L. (2009). Domino effect: domestic violence harms everyone's kids. Education Next, 9(3), 58-64. doi:10.1257/aer.20160763.

Carroll, A., Houghton, S., Durkin, K., \& Hattie, J. A. (2009). At-risk youth: Identifying, charting, and explaining the course of early involvement with crime. In Adolescent Reputations and Risk (pp. 1-16). Springer, New York, NY. https://doi.org/10.1007/978-0-387-79988-9_1

Ciucci, E., Baroncelli, A., Franchi, M., Golmaryami, F. N., \& Frick, P. J. (2014). The association between callous-unemotional traits and behavioral and academic adjustment in children: Further validation of the Inventory of Callous-Unemotional Traits. Journal of Psychopathology and Behavioral Assessment, 36(2), 189-200. doi: $10.1007 / \mathrm{s} 10862-013-9384-\mathrm{Z}$

Colder, C. R., Trucco, E. M., Lopez, H. I., Hawk Jr, L. W., Read, J. P., Lengua, L. J., ... \& Eiden, R. D. (2011). Revised reinforcement sensitivity theory and laboratory 
assessment of BIS and BAS in children. Journal of Research in Personality, 45(2), 198-207. https://doi.org/10.1016/j.jrp.2011.01.005

Dawel, A., O’Kearney, R., McKone, E., \& Palermo, R. (2012). Not just fear and sadness: Meta-analytic evidence of pervasive emotion recognition deficits for facial and vocal expressions in psychopathy. Neuroscience \& Biobehavioral Reviews, 36(10), 22882304. https://doi.org/10.1016/j.neubiorev.2012.08.006

DeLisi, M., Vaughn, M., Beaver, K. M., Wexler, J., Barth, A. E., \& Fletcher, J. M. (2011). Fledgling psychopathy in the classroom: ADHD subtypes, psychopathy, and reading comprehension in a community sample of adolescents. Youth Violence and Juvenile Justice, 9(1), 43-58. https://doi.org/10.1177/1541204010371932

Department for Education (2017). Schools, pupils and their characteristics: January 2017. 2017 School Census. Retrieved from https:// Www.gov.uk/government/statistics/schools-pupils-and-their- characteristicsjanuary2017.

Doll, B., Spies, R., \& Champion, A. (2012). Contributions of ecological school mental health services to students' academic success. Journal of Educational and Psychological Consultation, 22(1-2), 44-61. https://doi.org/10.1080/10474412.2011.649642

Doumen, S., Verschueren, K., Buyse, E., Germeijs, V., Luyckx, K., \& Soenens, B. (2008). Reciprocal relations between teacher-child conflict and aggressive behavior in kindergarten: A three-wave longitudinal study. Journal of Clinical Child \& Adolescent Psychology, 37(3), 588-599. https://doi.org/10.1080/15374410802148079

Essau, C. A., Sasagawa, S., \& Frick, P. J. (2006). Callous-unemotional traits in a community sample of adolescents. Assessment, 13(4), 454-469. https://doi.org/10.1177/1073191106287354

Frick, P. J. (2004). The inventory of callous-unemotional traits. Unpublished rating scale. 
Frick, P. J., Ray, J. V., Thornton, L. C., \& Kahn, R. E. (2014). Can callous-unemotional traits enhance the understanding, diagnosis, and treatment of serious conduct problems in children and adolescents? A comprehensive review. Psychological Bulletin, 140(1), 1-57. http://dx.doi.org/10.1037/a0033076

Fung, A. L. C., Gao, Y., \& Raine, A. (2009). The utility of the child and adolescent psychopathy construct in Hong Kong, China. Journal of Clinical Child \& Adolescent Psychology, 39(1), 134-140. https://doi.org/10.1080/15374410903401138

Garcia, A. M., Graziano, P. A., \& Hart, K. C. (2018). Response to time-out among preschoolers with externalizing behavior problems: The role of callous-unemotional traits. Child Psychiatry \& Human Development, 49(5), 699-708. https://doi.org/10.1007/s10578-018-0788-6

Goodman, R. (1997). The strengths and difficulties questionnaire: a research note. Journal of Child Psychology and Psychiatry, 38(5), 581-586. https://doi.org/10.1111/j.14697610.1997.tb01545.x

Hawes, D. J., \& Dadds, M. R. (2005). The treatment of conduct problems in children with callous-unemotional traits. Journal of Consulting and Clinical Psychology, 73(4), 737. https://doi.org/10.1037/0022-006X.73.4.737

Hawes, D. J., Price, M. J., \& Dadds, M. R. (2014). Callous-unemotional traits and the treatment of conduct problems in childhood and adolescence: A comprehensive review. Clinical Child and Family Psychology Review, 17(3), 248-267. doi: $10.1007 / \mathrm{s} 10567-014-0167-1$

Henry, K. L., Knight, K. E., \& Thornberry, T. P. (2012). School disengagement as a predictor of dropout, delinquency, and problem substance use during adolescence and early adulthood. Journal of Youth and Adolescence, 41(2), 156-166. doi: 10.1007/s10964011-9665-3 
Hiatt, K. D., \& Newman, J. P. (2006). Understanding psychopathy: The cognitive side. In C. J. Patrick (Ed.), Handbook of psychopathy (pp. 334-352). New York: The Guilford Press.

Hinshaw, S. P. (1992). Externalizing behavior problems and academic underachievement in childhood and adolescence: causal relationships and underlying mechanisms. Psychological Bulletin, 111(1), 127-155.

Horan, J. M., Brown, J. L., Jones, S. M., \& Aber, J. L. (2016). The influence of conduct problems and callous-unemotional traits on academic development among youth. Journal of Youth and Adolescence, 45(6), 1245-1260. doi: 10.1007/s10964$015-0349-2$

Hox, J., \& Bechger, T. (1998). An Introduction to Structural Equation Modelling. Family Science Review, 11,354-373.

Hu, L. T., \& Bentler, P. M. (1999). Cutoff criteria for fit indexes in covariance structure analysis: Conventional criteria versus new alternatives. Structural Equation Modeling: a Multidisciplinary Journal, 6(1), 1-55. https://doi.org/10.1080/10705519909540118

Hwang, S., Waller, R., Hawes, D.J., \& Allen, J.L. (in press). Callous-unemotional traits and antisocial behavior in South Korean children: Links with academic motivation, school engagement, and teachers' use of reward and discipline. Journal of Abnormal Child Psychology. doi: 10.1007/s10802-020-00663-2.

IBM Corp. Released 2017. IBM SPSS Statistics for Windows, Version 25.0. Armonk, NY: IBM Corp.

Johnson, D. T. (2000). Teaching mathematics to gifted students in a mixed-ability classroom. Reston, VA: ERIC Clearinghouse on Disabilities and Gifted Education. 
Jones, A. P., Laurens, K. R., Herba, C. M., Barker, G. J., \& Viding, E. (2009). Amygdala hypoactivity to fearful faces in boys with conduct problems and callous-unemotional traits. American Journal of Psychiatry, 166(1), 95-102. https://doi.org/10.1176/appi.ajp.2008.07071050

Kimonis, E. R., Frick, P. J., Skeem, J. L., Marsee, M. A., Cruise, K., Munoz, L. C., ... \& Morris, A. S. (2008). Assessing callous-unemotional traits in adolescent offenders: Validation of the Inventory of Callous-Unemotional Traits. International Journal of Law and Psychiatry, 31(3), 241-252. https://doi.org/10.1016/j.ijlp.2008.04.002

Kochanska, G. (1993). Toward a synthesis of parental socialization and child temperament in early development of conscience. Child Development, 64(2), 325-347.

https://doi.org/10.1111/j.1467-8624.1993.tb02913.x

Lewis, R., Romi, S., Qui, X., \& Katz, Y. J. (2005). Teachers' classroom discipline and student misbehavior in Australia, China and Israel. Teaching and Teacher Education, 21(6), 729-741. https://doi.org/10.1016/j.tate.2005.05.008

Lockwood, P. L., Sebastian, C. L., McCrory, E. J., Hyde, Z. H., Gu, X., De Brito, S. A., \& Viding, E. (2013). Association of callous traits with reduced neural response to others' pain in children with conduct problems. Current Biology, 23(10), 901-905. https://doi.org/10.1016/j.cub.2013.04.018

Loney, B. R., Frick, P. J., Ellis, M., \& McCoy, M. G. (1998). Intelligence, callousunemotional traits, and antisocial behavior. Journal of Psychopathology and Behavioral Assessment, 20(3), 231-247. https://doi.org/10.1023/A:1023015318156

Maguin, E., \& Loeber, R. (1996). Academic performance and delinquency. Crime and Justice, 20, 145-264. https://doi.org/10.1086/449243 
Meuleman, B., \& Billiet, J. (2009). A Monte Carlo sample size study: How many countries are needed for accurate multilevel SEM?. In Survey Research Methods (Vol. 3, No. 1, pp. 45-58).

Midgley, C., \& Urdan, T. (1992). The transition to middle level schools: Making it a good experience for all students. Middle School Journal, 24(2), 5-14.

https://doi.org/10.1080/00940771.1992.11495161

Moretti, E. (2005, September). Does education reduce participation in criminal activities. In Symposium on Social Costs of Inadequate Education, Teachers' College, Columbia University.

Muthén, L., Muthén, B.J.L.A., (2017). Mplus user's guide: Statistical analysis with latent variables, user's guide. Muthén \& Muthén.

Moffitt, T. E. (1993). Adolescence-limited and life-course-persistent antisocial behavior: a developmental taxonomy. Psychological Review, 100, 74-701. https://doi.org/10.1037/0033-295X.100.4.674

Nichols, S. R., Briggs-Gowan, M. J., Estabrook, R., Burns, J. L., Kestler, J., Berman, G., ... \& Wakschlag, L. S. (2015). Punishment insensitivity in early childhood: A developmental, dimensional approach. Journal of Abnormal Child Psychology, 43(6), 1011-1023. https://doi.org/10.1007/s10802-014-9950-1

Office for National Statistics (2017). Families and Households: 2017. 2017 Labour Force Survey. Retrieved from https://www.ons.gov.uk/peoplepopulationandcommunity/birthsdeathsandmarriages/ families/bulletins/familiesandhouseholds/2017

Ofsted (2013) Improving literacy in secondary schools: a shared responsibility. Retrieved from 
https://assets.publishing.service.gov.uk/government/uploads/system/uploads/attachme nt_data/file/413182/Improving_literacy_in_secondary_schools.pdf

Pardini, D. A., \& Byrd, A. L. (2012). Perceptions of aggressive conflicts and others' distress in children with callous-unemotional traits: 'I'll show you who's boss, even if you suffer and I get in trouble'. Journal of Child Psychology and Psychiatry, 53(3), 283291. https://doi.org/10.1111/j.1469-7610.2011.02487.x

Pardini, D., \& Frick, P. J. (2013). Multiple developmental pathways to conduct disorder: Current conceptualizations and clinical implications. Journal of the Canadian Academy of Child and Adolescent Psychiatry, 22(1), 20-25.

Pasternak, R. (2013). Discipline, learning skills and academic achievement. Journal of Arts and Education, 1(1), 1-11.

Ray, J. V., Frick, P. J., Thornton, L. C., Steinberg, L., \& Cauffman, E. (2016). Positive and negative item wording and its influence on the assessment of callous-unemotional traits. Psychological Assessment, 28(4), 394-404. https://doi.org/10.1037/pas0000183

Romi, S., Lewis, R., \& Roache, J. (2013). Classroom management and teachers' coping strategies: Inside classrooms in Australia, China and Israel. Prospects, 43(2), 215231. doi: $10.1007 / \mathrm{s} 11125-013-9271-0$

Roose, A., Bijttebier, P., Decoene, S., Claes, L., \& Frick, P. J. (2010). Assessing the affective features of psychopathy in adolescence: a further validation of the inventory of callous and unemotional traits. Assessment, 17(1), 44-57. https://doi.org/10.1177/1073191109344153

Salmela-Aro, K., \& Upadyaya, K. (2014). School burnout and engagement in the context of demands-resources model. British journal of Educational Psychology, 84(1), 137151.

https://doi.org/10.1111/bjep.12018 
Schunck, R. (2016). Cluster size and aggregated level 2 variables in multilevel models. A cautionary note. Methods, Data, Analyses, 10(1), 97-108. https://doi.org/10.12758/mda.2016.005

Slater, H., Davies, N. M., \& Burgess, S. (2012). Do teachers matter? Measuring the variation in teacher effectiveness in England. Oxford Bulletin of Economics and Statistics, 74(5), 629-645.

https://doi.org/10.1111/j.1468-0084.2011.00666.x

Sng, K. I., Hawes, D. J., Hwang, S., Allen, J.L., \& Fung, D.S.S. (2020). Callous-

unemotional traits among children and adolescents in Asian cultures: A systematic review. Journal of Cross-Cultural Psychology, 51(7-8), 576-596. https://doi.org/10.1177/0022022120944475

Sng, K. I., Hawes, D. J., Raine, A., Ang, R. P., Ooi, Y. P., \& Fung, D. S. (2018). Callous unemotional traits and the relationship between aggressive parenting practices and conduct problems in Singaporean families. Child Abuse and Neglect, 81, 225-234. https://doi.org/10.1016/j.chiabu.2018.04.026

Spilt, J. L., Koomen, H. M., \& Thijs, J. T. (2011). Teacher wellbeing: The importance of teacher-student relationships. Educational Psychology Review, 23(4), 457-477. https://doi.org/10.1007/s10648-011-9170-y

Stodolsky, S. S., \& Grossman, P. L. (1995). The impact of subject matter on curricular activity: An analysis of five academic subjects. American Educational Research Journal, 32(2), 227-249. https://doi.org/10.3102/00028312032002227

Torrubia, R., Avila, C., Moltó, J., \& Caseras, X. (2001). The Sensitivity to Punishment and Sensitivity to Reward Questionnaire (SPSRQ) as a measure of Gray's anxiety and impulsivity dimensions. Personality and Individual Differences, 31(6), 837-862. https://doi.org/10.1016/S0191-8869(00)00183-5 
Vandeweghe, L., Matton, A., Beyers, W., Vervaet, M., Braet, C., \& Goossens, L. (2016). Psychometric properties of the BIS/BAS Scales and the SPSRQ in Flemish adolescents. Psychologica Belgica, 56(4), 406-420. doi: 10.5334/pb.298

Vaughn, M. G., DeLisi, M., Beaver, K. M., Wexler, J., Barth, A., \& Fletcher, J. (2011). Juvenile psychopathic personality traits are associated with poor reading achievement. Psychiatric Quarterly, 82(3), 177-190. https://doi.org/10.1007/s11126010-9162-y

Wakschlag, L. S., Choi, S. W., Carter, A. S., Hullsiek, H., Burns, J., McCarthy, K., ... \& Briggs-Gowan, M. J. (2012). Defining the developmental parameters of temper loss in early childhood: implications for developmental psychopathology. Journal of Child Psychology and Psychiatry, 53(11), 1099-1108. https://doi.org/10.1111/j.14697610.2012.02595.x

Warren, L., Jones, A., \& Frederickson, N. (2015). Callous-unemotional interpersonal style in DSM-V: what does this mean for the UK SEBD population?. Emotional and Behavioural Difficulties, 20(3), 317-330. https://doi.org/10.1080/13632752.2014.964084

Westling, D. L. (2010). Teachers and challenging behavior: Knowledge, views, and practices. Remedial and Special Education, 31, 48-63. https://doi.org/10.1177/0741932508327466

Yang, K. W. (2009). Focus on policy: Discipline or punish? Some suggestions for school policy and teacher practice. Language Arts, 87(1), 49-61. 

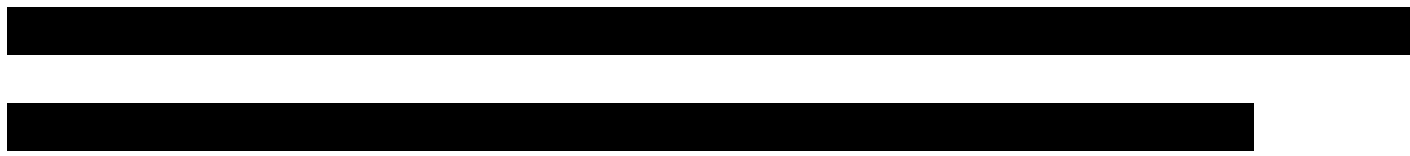

(blinded for peer review)

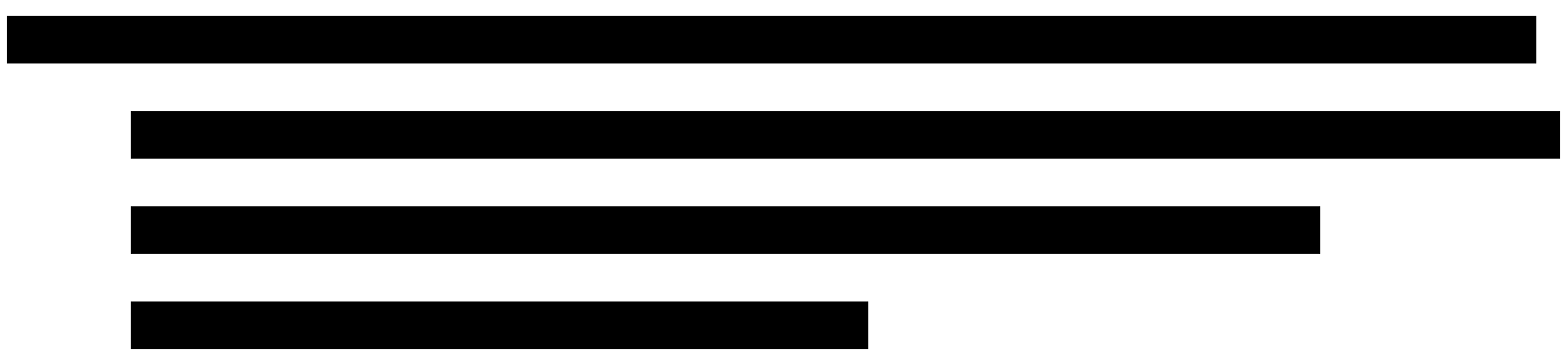

(blinded for peer review) 
Table 1

Descriptive Statistics and Correlations between the Study Variables

\begin{tabular}{|c|c|c|c|c|c|c|c|c|c|c|c|c|c|}
\hline Variables & $\mathrm{N}$ & $\mathrm{M}(\mathrm{SD})$ & 1. & 2. & 3. & 4. & 5. & 6. & 7. & 8. & 9. & 10. & 11. \\
\hline 1. Age & 437 & $12.50(0.96)$ & 1 & & & & & & & & & & \\
\hline 2. Gender (Female) & 437 & - & .04 & 1 & & & & & & & & & \\
\hline 3. Single Parent & 434 & - & .08 & -.06 & 1 & & & & & & & & \\
\hline 4. Free School Meals & 427 & - & -.07 & $-.13 * *$ & $.14 * *$ & 1 & & & & & & & \\
\hline 5. English as First Language & 431 & - & -.07 & -.01 & .09 & -.04 & 1 & & & & & & \\
\hline 6. Externalizing Problems & 436 & $0.00(1.00)$ & -.06 & $-.14 * *$ & .04 & .06 & -.03 & 1 & & & & & \\
\hline 7. CU traits & 435 & $21.28(7.88)$ & .09 & $-.14 * *$ & .07 & $.12 *$ & -.02 & $.21 * *$ & 1 & & & & \\
\hline 8. Punishment Insensitivity & 437 & $14.54(6.55)$ & -.01 & $-.12 *$ & $.12 *$ & $.14 * *$ & -.01 & $.55^{* *}$ & $.59 * *$ & 1 & & & \\
\hline 9. English Grade & 414 & $3.65(1.37)$ & $-.46 * *$ & $.16^{* *}$ & -.06 & -.05 & -.05 & $-.06^{*}$ & $-.16 * *$ & $-.13 * *$ & 1 & & \\
\hline 10. Math Grade & 414 & $3.90(1.20)$ & $-.14 * *$ & .02 & $-.15^{* *}$ & -.05 & $-.11 *$ & $-.19 * *$ & $-.18 * *$ & $-.31 * *$ & $.53 * *$ & 1 & \\
\hline 11. Science Grade & 420 & $4.08(1.04)$ & .09 & .09 & $-.15^{* *}$ & $-.17 * *$ & $-.15 * *$ & $-.19 * *$ & $-.22 * *$ & $-.33 * *$ & $.41 * *$ & $.72 * *$ & 1 \\
\hline
\end{tabular}

Note. ${ }^{*} p<0.05 .{ }^{*} p<<0.01 ; \mathrm{CU}$ traits $=$ Callous-unemotional traits. 
Fully-adjusted paths for all academic outcomes

Parameter

\section{Parameter}

B

SE

$\boldsymbol{\beta}$

$95 \% \mathrm{CI}$

Direct paths to English

Punishment Insensitivity $\rightarrow$ English

$-.02$

CU traits $\rightarrow$ English

$-.01$

Age $\rightarrow$ English

$-.62$

Gender $\rightarrow$ English

Single Parent $\rightarrow$ English

$-.00$

Free School Meals $\rightarrow$ English

English as First Language $\rightarrow$ English

Externalizing problems $\rightarrow$ English

.00

$-.01$

Age $\rightarrow$ Maths

Gender $\rightarrow$ Maths

Single Parent $\rightarrow$ Maths

Free School Meals $\rightarrow$ Maths

English as First Language $\rightarrow$ Maths

Externalizing problems $\rightarrow$ Maths

\section{Direct paths to Science}

Punishment Insensitivity $\rightarrow$ Science

CU traits $\rightarrow$ Science

Age $\rightarrow$ Science

Gender $\rightarrow$ Science

Single Parent $\rightarrow$ Science

Free School Meals $\rightarrow$ Science

English as First Language $\rightarrow$ Science

Externalizing problems $\rightarrow$ Science

Direct paths to Punishment insensitivity

CU traits $\rightarrow$ Punishment Insensitivity
.09
.06

.01

.01

.06

.12

.16

.06

.01

.01

.05

.10

.12

.17

.11

.06

.04
$-.08$

$-.04, .00$

$-.05$

$-.03, .01$

$-.44 * * *$

$-.75,-.48$

$-.15^{* * *}$

$-.65,-.19$

.01

$-.31, .27$

$-.06$

$-.58, .04$

$.08^{*}$

$.01, .52$

.01

$-.12, .12$

$-.27 * * * \quad-.08,-.02$

$-.01$

$-.02, .02$

$-.15^{* *}$

$-.31,-.06$

.03

$-.16, .31$

$-.10^{*}$

$-.66,-.03$

$-.01$

$-.38, .31$

$.11 *$

$.07, .61$

$-.06$

$-.18, .04$

$.23 * * *$

$-.06,-.02$

$-.05$

$-.02, .01$

.08

$-.02, .20$

$-.02$

$-.23, .15$

$-.10 *$

$-.53,-.05$

$-.10^{*}$

$-.68,-.02$

$.14 * *$

$.12, .55$

$-.05$

$-.16, .06$

Note. ${ }^{*} p<0.05 . * * p<0.01 . * * * p<0.001$. CU traits = Callous-unemotional traits. Dummy codes for each classroom were included as control variables in the model but these are not shown in the table. 
$\underline{\text { Table } 3}$

Total, Direct, and Indirect effects of Punishment Insensitivity on Academic Achievement

\begin{tabular}{lcccccc}
\hline & \multicolumn{2}{c}{ English } & \multicolumn{2}{c}{ Maths } & \multicolumn{2}{c}{ Science } \\
\cline { 2 - 7 } & $\beta(\mathrm{SE})$ & $95 \% C I$ & $\beta(\mathrm{SE})$ & $95 \% \mathrm{CI}$ & $\beta(\mathrm{SE})$ & $95 \% C I$ \\
\hline Total Effect & $-.08(.01)$ & $-.169, .000$ & $-.14(.01)^{* *}$ & $-.254,-.040$ & $-.16(.01)^{* *}$ & $-.255,-.067$ \\
Direct Effect & $-.05(.01)$ & $-.145, .052$ & $-.01(.01)$ & $-.126, .109$ & $-.05(.01)$ & $-.153, .057$ \\
Indirect Effect & $-.04(.00)$ & $-.086, .009$ & $-.13(.01)^{* * *}$ & $-.211,-.064$ & $-.11(.00)^{* *}$ & $-.185,-.050$ \\
\hline
\end{tabular}

Note. ${ }^{* * p} p<0.01 . * * p<0.001$.

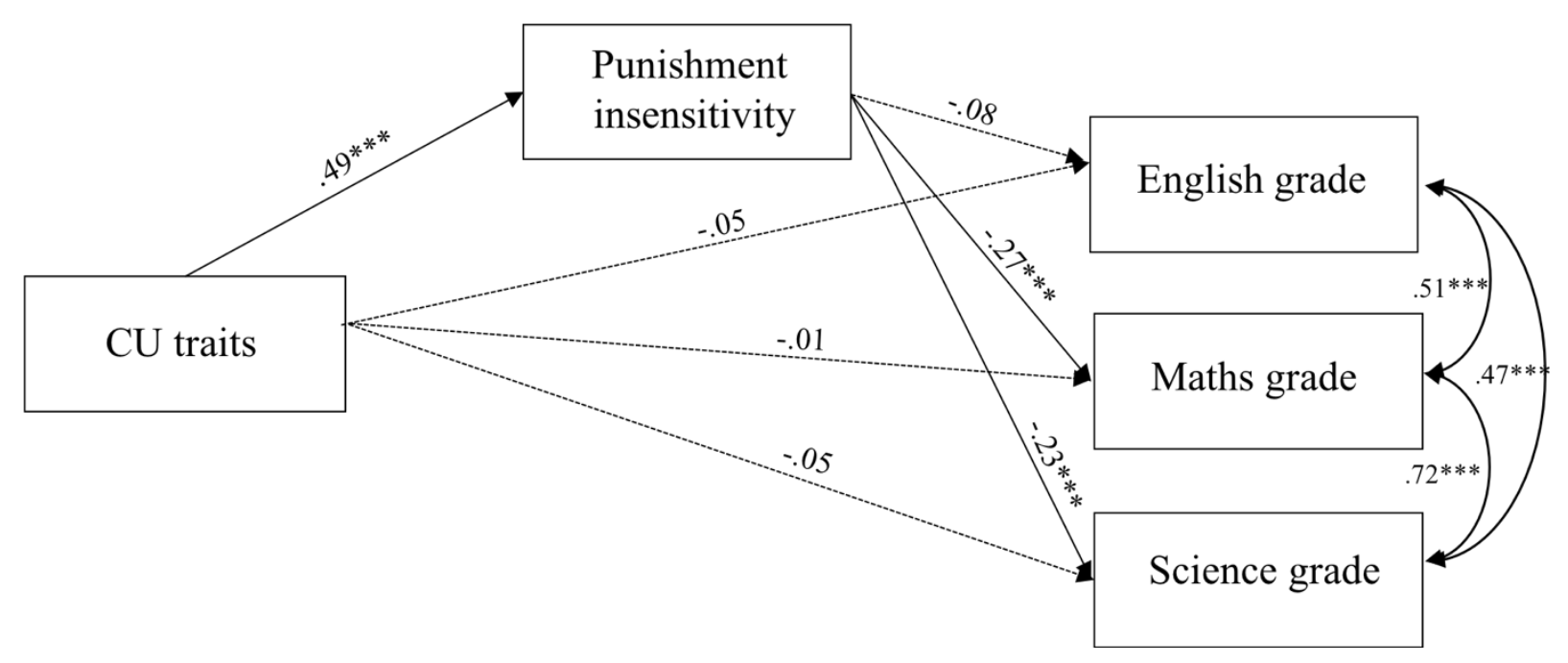

Figure 1.

Structural equation model to depict indirect associations between CU traits and academic grades via punishment insensitivity.

Child age, gender, single parent, free school meal, language, externalising problems, and classroom effects were entered as control variables, but these are not shown. Standardized coefficients are presented. Double-sided arrows present covariances between outcomes.

$* * p<.01 . * * * p<.001$. 